\title{
Biological and physical factors influencing genotype-dependent mortality in hybrid mussel populations
}

\author{
J. P. A. Gardner*, D. O. F. Skibinski \\ School of Biological Sciences, University College of Swansea, Singleton Park, Swansea SA2 8PP, United Kingdom
}

\begin{abstract}
Biological (predation) and physical (wave action) factors influencing mortality of Mytilus edulis and M. galloprovincialis mussel types within hybrid and pure populations were investigated with the aim of identifying possible selective factors responsible for observed length-and age-dependent genotypic variation. In laboratory tests, shore crabs Carcinus maenas did not significantly prefer any type when choosing between mussels from a hybrid population. When presented with edulis and galloprovincialis from allopatric populations the crabs expressed no significant preference for either mussel type. Neither crab sex nor crab size significantly affected mussel type chosen. Dogwhelks also did not express a significant preference for mussel type when feeding upon mussels of a hybrid population, but did exhibit significant preference for edulis over galloprovincialis from pure populations. Mussel strength of attachment (SOA) to the substrate was tested in 2 hybrid mussel populations, Croyde and Whitsand in SW England. Shell length and genotype, but not population, explained significant variation in SOA. At all lengths, edulis-like mussels had a significantly lower SOA than galloprovincialis-like mussels. Overall, these results suggest that neither predator is likely to be responsible for the higher frequency of galloprovincialis in larger and older mussels of mixed populations. However, the SOA data indicate that this physical factor, which is related to site-specific wave action, is correlated with genotype-dependent mortality. It is concluded that the strong negative correlation between edulis frequency and length (and also age) in many hybrid populations results partly from a slight galloprovincialis growth advantage (measured by in situ growth experiments), but mainly from selective mortality of edulis individuals.
\end{abstract}

\section{INTRODUCTION}

Predators have been shown to have very considerable impact upon molluscan populations, in terms of both controlling structure and regulating density, as well as in creating space. For example, in many areas the lower limits on the shore of distribution of the blue mussel Mytilus edulis are thought to be set by predation (e.g. Suchanek 1978). Much of the research involving both biological and physical factors influencing $M$. edulis mortality has been carried out on the west coast of North America (e.g. Harger 1972, Suchanek 1978). Recently, McDonald \& Koehn (1988) have suggested that $M$. edulis is in fact $M$. galloprovincialis in southern California, $M$. trossulus in regions north of Oregon, and hybrids of these 2 forms in central and northern Califor-

- Present address: Department of Zoology, University of Leicester, Leicester LEl 7RH, UK nia. However, in this paper the nomenclature of the original papers will be followed.

In the lower intertidal and subtidal regions of the Pacific rocky shore of Washington State, USA, in areas where predation is high, Mytilus edulis achieves a maximum size of ca $40 \mathrm{~mm}$, compared to a maximum length of approximately $140 \mathrm{~mm}$ where there is no predation (Suchanek 1978). In other regions where the ribbed mussel Mytilus californianus dominates, $M$. edulis may colonize and grow rapidly where primary space is created. However, in such regions, selective predation of $M$. edulis, in preference to $M$. californianus, by sea stars, birds and gastropods totally eliminates $M$. edulis from large patches (Harger 1972). Thus, the population dynamics of $M$. edulis and $M$. californianus on the Pacific coast of North America are at least partially controlled by predation.

Other instances of the control of bivalve population structure by predators have been documented. For 
example, Wickens \& Griffiths (1985) described predation by the whelk Nucella cingulata upon 3 species of intertidal mussels in South Africa, where N. cingulata feeds upon Aulacomya ater in preference to Choromytilus meridionalis and Perna perna, so affecting the spatial dynamics of all 3 species. In north Wales, Sanchez-Salazar et al. (1987) showed that the green shore crab Carcinus maenas and the oystercatcher Haematopus ostralegus play a significant role in structuring populations of the edible cockle Cerastoderma edule, each by actively preying upon different sized cockles at different times of the year.

Physical, as well as biological, processes are known to be able to significantly affect marine molluscan population structure. For example, Harger (1970) has demonstrated that in California, USA, the force necessary to tear Mytilus californianus loose from the substrate is greater than that needed to tear $M$. edulis loose. The implication of this species-specific difference in strength of attachment (SOA) is that in exposed areas only small $M$. edulis can survive, whereas larger $M$. edulis occur in more sheltered regions, such as estuaries and harbours. In conditions of extreme exposure such as the Monterey Peninsula, California, $M$. edulis is entirely absent (Harger 1972). However, $M$. californianus of all sizes can withstand wave impact such that no size limitation is imposed by wave action on this species. Thus, wave action, acting upon morphological differences, structures the $M$. edulis and $M$. californianus populations. Other examples of physical factors structuring molluscan populations have been provided by Dayton (1971), Shanks \& Wright (1986), and Landahl (1988).

Seed (1978) observed that many of the characteristics associated with epifaunal life are particularly apparent in the Mediterranean mussel Mytilus galloprovincialis. Furthermore, these same characteristics are most pronounced in older mussels suggesting that these features are of adaptive value. Similar trends are observed in other bivalve lineages (e.g. Yonge \& Campbell 1968). More specifically, Skibinski (1983) proposed that the pattern of length-dependent allele frequencies in hybrid edulis/galloprovincialis populations from SW England could be explained by differences in SOA between $M$. edulis and $M$. galloprovincialis, possibly derived from the morphological differences between the 2 mussel types.

In this paper we investigate possible mechanisms by which the strong positive correlation between galloprovincialis allele frequency and shell length is generated and maintained in 2 hybrid Mytilus edulis and $M$. galloprovincialis populations at Croyde Bay, north Devon, and at Whitsand Bay, south Cornwall, in SW England. We test the hypotheses that mussel predators cause the correlation by preying differentially upon edulis of the hybrid populations, and that the correlation is generated by genotype-dependent differences in mussel strength of attachment to the substrate.

\section{MATERIALS AND METHODS}

Carcinus maenas predation against Croyde mussels. During monthly visits to Croyde and Whitsand throughout 1987 and 1988 a visual search for shore crabs was carried out to estimate crab population density. Other sampling methods were inappropriate because of the very low population density and because crabs were only found in crevices or holes.

In mid-August 1988, 14 green shore crabs Carcinus maenas were collected from sites near Swansea, South Wales (mean \pm SD carapace width $[\mathrm{mm}] 56.8 \pm 4.5$ ), of which 7 were male $(56.6 \mathrm{~mm} \pm 4.7)$ and 7 female $(57.0 \mathrm{~mm} \pm 4.8)$. The crabs were transferred to the University sea water facility where a re-circulating system is maintained at ambient conditions. Each crab was held in a 2.51 plastic container, and provided with constant aeration and water exchange. Sieved sand to a depth of ca $1 \mathrm{~cm}$ was placed in each container before the crab was introduced (e.g. Sanchez-Salazar et al. 1987). The sex and maximum carapace width (size) of each crab were recorded. Black plastic mesh (mesh size $1.5 \mathrm{~cm}$ ) was anchored over each container to prevent crab escapes.

A large sample of mussels from the hybrid Croyde population was collected in mid-August 1988, and returned to the University sea water facility. These mussels were held in a $50 \mathrm{l}$ plastic container with constant aeration and water exchange. The mussels used were thoroughly cleaned of fouling organisms.

After a period of $3 \mathrm{~d}$ starvation for all crabs to standardize hunger levels (e.g. ap Rheinallt 1986), 2 Croyde mussels of equal length (in the range 13.4 to $40.5 \mathrm{~mm}$ ) were offered to each crab. The mussels were placed in identical orientation and equidistant from each crab. The crab was allowed to select one of the 2 mussels and to start to prey upon it, at which time this 'accepted' mussel was removed. The other 'rejected' mussel was also removed, and both mussels were saved for allozyme analysis. In this manner, over a period of several weeks, 140 pairs of 'accepted' and 'rejected' mussels were obtained ( $n=280$ individuals). Samples were analysed immediately or stored at $-70^{\circ} \mathrm{C}$ for subsequent analysis. Following each preference test, each crab was fed one crushed mussel; shell fragments were removed at regular intervals. Starch gel electrophoresis was performed on hepatopancreas tissue prepared as described by Gardner \& Skibinski (1988). Two polymorphic allozyme loci, Esterase-D (Est-D; EC 3.1.1.1) and Octopine dehydrogenase (Odh; EC 
1.5.1.11) were stained for. These are amongst the most diagnostic loci for edulis and galloprovincialis (Skibinski 1983, Gardner \& Skibinski 1988).

To aid in data analysis compound alleles as defined by Skibinski (1983) were employed. At a given locus the compound $E$ allele is obtained by pooling those alleles at highest frequency in Mytilus edulis and the compound $G$ allele is obtained by pooling those alleles at highest frequency in $M$. galloprovincialis. Thus, for these 2 loci there are 9 genotype combinations, from the most edulis-like ( $E / E E / E)$, through the intermediate $(E / G E / G)$ to the most galloprovincialis-like $(G / G$ $G / G)$. The use of compound alleles permits data analysis in 2 separate ways. Firstly, it allows comparison of the effect of dilocus genotype ( $E / E E / E$ vs $E / G E / G$ vs $G / G G / G$ upon the variable being tested. These comparisons are of interest as they involve putative parental and Fl genotypes: however, individuals of the other 6 possible dilocus genotype combinations are excluded from the analysis. Secondly, the effect of genotype according to the number of $E$ alleles per individual can be used which avoids wastage of data. Thus, $5 E$ categories exist, EO to E4, where EO represents only $G / G G / G$ mussels, and $E 4$ represents only $E / E E / E$ mussels. The E1 category is composed of $E / G G / G$ and $G / G E / G$ individuals, the $\mathrm{E} 2$ category of $E / G E / G, G / G$ $E / E$ and $E / E G / G$ mussels, and the $E 3$ category of $E / E$ $E / G$ and $E / G E / E$ mussels. To test for genotype-specific preferences expressed by the crabs when feeding upon the mussels, the frequency of edulis-like genes as a function of shell length amongst 'accepted' mussels was compared with that amongst the 'rejected' mussels using a contingency test employing Williams' correction (Sokal \& Rohlf 1981).

Carcinus maenas predation against edulis and galloprovincialis mussels. Large samples of mussels from Caswell, South Wales (a Mytilus edulis population) and from Bude, SW England (a M. galloprovincialis population), were collected in mid-August 1988, and returned to the University sea water facility. Each sample was held separately as described for the Croyde mussels (previous section).

Crabs from the collections previously described, and held as previously described, were provided with one mussel from Bude and an equal sized mussel from Caswell. These mussels were distinguished on the basis of shell morphology (e.g. Seed 1971). The size range of mussels used was 15 to $33 \mathrm{~mm}$, with a mean length $\pm \mathrm{SD}$ of $24.5 \pm 3.4 \mathrm{~mm}(\mathrm{n}=98$ ). The mussels were placed equidistant from the crab, and in the same orientation. The crabs were allowed to move from one mussel to the other, but to feed upon only one mussel. The breaking time, $T_{\mathrm{b}}$ (time from first contact with the mussel to time of first eating the flesh), the eating time, $T_{\mathrm{e}}$ (time taken to eat the mussel), and the handling time, $T_{\mathrm{h}}\left(T_{\mathrm{b}}+T_{\mathrm{e}}\right)$ were all recorded (e.g. Seed 1982 , Davidson 1986, Sanchez-Salazar et al. 1987). The uneaten mussel was removed. A total of 98 mussels were subjected to crab predation. Following choice experiments, the crabs were each fed a crushed mussel and fragments of shell were removed at daily intervals.

Data were analyzed to determine if the crabs expressed a preference for either mussel type, and to determine if crab sex and/or size had a significant effect upon type of mussel consumed, and time taken to consume the mussel. A comparison of $T_{\mathrm{b}}, T_{\mathrm{e}}$ and $T_{\mathrm{h}}$ was made to assess the relative ease and speed with which the crabs preyed upon the 2 mussel types. Regression analysis of $T_{\mathrm{b}}$ (dependent variable) as a function of shell length (covariate), with crab sex and mussel genotype (independent variables) was performed to estimate how much variation in $T_{\mathrm{b}}$ could be explained by these other factors. A similar procedure was followed for $T_{\mathrm{e}}$ and $T_{\mathrm{h}}$, each as dependent variable in place of $T_{\mathrm{b}}$.

Nucella lapillus predation against Croyde mussels. In mid-September 1988, dogwhelk surveys were carried out at Croyde ( $\mathrm{n}=37$ quadrats) and Whitsand ( $\mathrm{n}=$ 23 quadrats). All whelks within each random $10 \mathrm{~cm}^{2}$ quadrat were collected, measured for spire height and returned to the University sea water facility. They were held in a 2.51 plastic container under ambient conditions with constant aeration and water exchange.

Dogwhelks were held without food for $7 \mathrm{~d}$ to standardize hunger levels. One dogwhelk was placed in each of 56 pyrex $250 \mathrm{ml}$ beakers, with 2 Croyde mussels of equal length (collected in mid-August). Mussels of $>25 \mathrm{~mm}$ were used because edulis and galloprovincialis genotype frequencies are approximately equal at 25 to $35 \mathrm{~mm}$ at Croyde (Gardner \& Skibinski 1988). Mussels were judged to be edulis- or galloprovincialislike on the basis of morphological criteria, although some of the pairwise mussel preference tests will inevitably have involved mussels of the same type. To prevent dogwhelk escape, a plastic cover measuring $56 \times 60 \mathrm{~cm}$ with a $1 \mathrm{~cm}$ rim was placed over the beakers. Each beaker was positioned under a hole of ca $1 \mathrm{~cm}$ diameter, through which aerated seawater was allowed to flow into each beaker. Excess water escaped through the beaker lip. Dogwhelks were checked every day, and when one mussel had been drilled and eaten, both mussels were removed. A total of 102 pairwise choice experiments were performed. The drilled 'accepted' mussel shells were discarded, whereas the remaining 'rejected' live mussel was kept at $-70^{\circ} \mathrm{C}$ for subsequent electrophoresis. Compound allele nomenclature was used for data analysis. A regression analysis of arcsine transformed $E$ allele frequency of the 'rejected' mussels as a function of shell length (divided into $5 \mathrm{~mm}$ size classes: $25-29.9 \mathrm{~mm}, 30-34.9 \mathrm{~mm}$, etc.) 
was performed for (1) the Est-D locus, (2) the Odh locus and (3) the dilocus genotype. Each of the 3 equations was compared with an equation of the same nature obtained from our previous historical comparison study (Gardner \& Skibinski 1988) which acted as a control. A single classification covariance analysis (Sokal \& Rohlf 1981) was carried out to determine if significant differences existed between the 'rejected' $E$ allele frequencies and the control $E$ allele frequencies as a function of length, indicating a dogwhelk preference for either type of mussel. The 1986/87 study (Gardner \& Skibinski 1988) provides the largest sample sizes available for data on the length-dependent change in compound $E$ allele frequency. By comparing $E$ allele frequency as a function of length for the 'rejected' mussels with that of the Croyde population, we are testing for deviation of the experimental data from the known relationship between $E$ allele frequency and length observed in the field. By testing one edulis-like mussel against one galloprovincialis-like mussel of equal size (and therefore of approximately equal age too: Gardner 1989, Gardner \& Skibinski 1991) we simulated in the laboratory the choice that dogwhelks are faced with in the wild. Because the 2 test mussels were of approximately equal age they had survived the same period of time at Croyde during which they were subject to predation pressure.

Nucella lapillus predation against edulis and galloprovincialis mussels. Using the experimental design just described, each of 56 dogwhelks was provided with one Mytilus galloprovincialis mussel from Bude and one $M$. edulis mussel from Caswell. The mussels were of equal length and identifiable on the basis of shell morphology. The dogwhelks were checked almost every day, and the number of drilled mussels of each type was recorded. Drilled mussels were replaced by a mussel of similar size from the same population. In this manner a total of 84 mussels were subject to predation. A Chi-square analysis was employed to test for differences in the number of each mussel type which were preyed upon.

Morphometric analysis of edulis and galloprovincialis mussels. Thirty individuals from the Bude collection and 30 mussels from the Caswell collection, representative of the size range present in either collection, were compared morphometrically. Shell length, shell curve, dry shell weight and dry body weight were measured. The vertical displacement of the mid-point of each valve, from a line connecting the anterior and posterior of the dorsal edge of the shell, was measured, so that shell curve could be used as an index of shell shape. The 2 populations were compared for differences in each of the 4 variables using t-tests. These data were obtained to help explain predator response to the edulis and galloprovincialis mussels.
Strength of attachment analysis. An analysis of mussel strength of attachment (SOA) to the substrate was made at Whitsand on 13 September, and at Croyde on 14 September, 1988. One hundred mussels were tested at each site. An adjustable retort clamp was positioned around a single mussel without damaging or altering the position of the mussel or its neighbours. A Salter spring balance measuring up to $10 \mathrm{~kg}$ in $100 \mathrm{~g}$ intervals was attached to the retort clamp. Force was applied to the balance in a direction perpendicular to the face of attachment. A smooth and constant rate of increase of force was applied to the balance until the mussel was removed from the rock surface (e.g. Harger 1970). The force at which dislodgement occurred was recorded. Each mussel was saved for electrophoresis as previously described. From each site, 98 mussels gave scorable results at both loci, so the analysis of genotypedependent SOA is based upon a total of 196 individuals. Regression analysis of SOA (dependent variable) and shell length (independent variable) was carried out and the effects of genotype and site upon SOA were tested for. Genotype was scored according to both dilocus genotype and number of $E$ alleles per mussel.

\section{RESULTS}

\section{Carcinus maenas survey}

Very few shore crabs were located at either Croyde or Whitsand. Those that were found were small ( $<50 \mathrm{~mm}$ carapace width) compared with the crabs collected from less exposed sites in South Wales.

\section{Carcinus maenas predation against Croyde mussels}

Of the 140 'accepted' and 140 'rejected' mussels, 138 'accepted' and 133 'rejected' mussels were successfully electrophoresed at both loci. Despite the wide size range of mussels employed to counteract the lengthdependent genotype frequencies, the distribution of genotypes in both 'accepted' and 'rejected' categories was heavily biased towards edulis. Because of this, comparison of 'accepted' versus 'rejected' dilocus genotypes has not been made. According to the number of $E$ alleles per 'accepted' individual there were 111 mussels in the E4 group, 23 in the E3 group, 4 in the $E 2$ group, and 0 in both the $E 1$ and $E O$. In the 'rejected' category there were 97 mussels in the E4 group, 28 in the E 3 group, 8 in the E2 group, and 0 in both the E 1 and E 0 groups. The genotypic distributions for 'accepted' and 'rejected' mussels are not significantly different $(G=2.632, \mathrm{df}=2, p>0.25)$. In further experiments, mussels of the 25 to $35 \mathrm{~mm}$ category only 
(in which range edulis and galloprovincialis frequencies are approximately equal) might be more successfully used. Such a mussel size range was not solely used because the preferred mussel size range for predation by Carcinus maenas is 15 to $25 \mathrm{~mm}$ (Elner \& Hughes 1978, Seed 1980, Jubb et al. 1983). It was assumed that amongst mussels of 25 to $35 \mathrm{~mm}$ there would be an approximately equal frequency of edulislike and galloprovincialis-like mussels, but even here the distribution was heavily biased towards edulis in the 'accepted' and 'rejected' categories.

\section{Carcinus maenas predation against edulis and galloprovincialis mussels}

A total of 98 mussels were subject to crab feeding activity. Of these, 44 were edulis and 54 galloprovincialis, indicating that the crabs did not express a significant preference for either mussel type $\left(\chi^{2}=1.020\right.$, df $=$ $1, \mathrm{p}>0.10)$.

Crab sex did not significantly effect mussel-type preference amongst edulis $\left(\chi^{2}=0.091\right.$, df $=1, p>$ $0.50)$, amongst galloprovincialis $\left(\chi^{2}=0.296\right.$, df $=1, p>$ $0.50)$, or when the 2 mussel types are pooled $\left(\chi^{2}=\right.$ $0.367, \mathrm{df}=1, \mathrm{p}>0.50$ ). Thus male and female crabs ate approximately equal numbers of edulis and galloprovincialis. Furthermore, crab size (carapace width) did not significantly affect the choice of mussel type i.e. large and small crabs did not prefer different mussel types ( $t$-test comparison of mean carapace width of crabs which preferred edulis vs those preferred galloprovincialis; $t=0.559, \mathrm{df}=96, \mathrm{p}>0.50$ ). Mean size of preferred edulis versus mean size of preferred galloprovincialis was not significantly different $(t=1.665$, $\mathrm{df}$ $=96, \mathrm{p}>0.05$ ).

Breaking time $\left(T_{\mathrm{b}}\right)$, eating time $\left(T_{\mathrm{e}}\right)$ and handling time $\left\{T_{h}\right)$ all described an asymptotic curvilinear rela- tionship with mussel length. The correlations of $\log _{e}$ transformed $T_{\mathrm{b}}, T_{\mathrm{e}}$ and $T_{\mathrm{h}}$ with $\log _{\mathrm{e}}$ transformed shell length were all significant. For $\log _{e} T_{\mathrm{b}}, \mathrm{R}=0.230$ ( $\mathrm{n}=$ 98, $\mathrm{p}<0.025)$, for $\log _{\mathrm{e}} T_{\mathrm{e}}, \mathrm{R}=0.367(\mathrm{n}=98, \mathrm{p}<0.001)$, and for $\log _{e} T_{\mathrm{h}}, \mathrm{R}=0.336(\mathrm{n}=98, \mathrm{p}<0.001)$. The mean $T_{\mathrm{b}}$ of predated edulis was significantly greater than that of predated galloprovincialis $(t=2.411, \mathrm{df}=96$, $\mathrm{p}<0.02$ ), but mean $T_{\mathrm{e}}$ and mean $T_{\mathrm{h}}$ were not significantly different $(t=0.763, \mathrm{df}=96, \mathrm{p}>0.40$; and $t=$ 0.938 , df $=96, p>0.20$, respectively). The mean $T_{b}$ of edulis was $807.9 \mathrm{~s}$ ( $\pm \mathrm{SD} 668.9, \mathrm{n}=44$ ) compared with a mean $T_{\mathrm{b}}$ of galloprovincialis of $528.5 \mathrm{~s}$ ( $\pm 419.1, \mathrm{n}=$ 54). This does not reflect a difference in mean length of predated edulis versus galloprovincialis (see previous paragraph)

\section{Nucella lapillus survey}

At both sites the mean density of dogwhelks was greater on the low shore than on the mid shore, but neither difference was significant (at Croyde, $t=1.548$, $\mathrm{df}=35, \mathrm{p}>0.1 ;$ at Whitsand, $t=0.798, \mathrm{df}=21, \mathrm{p}>$ 0.4 ). Mean density (number of individuals $0.01 \mathrm{~m}^{-2}$ ) \pm $\mathrm{SD}$ and mean spire height $(\mathrm{mm}) \pm \mathrm{SD}$ were $4.1 \pm 7.5$ ( $\mathrm{n}=37$ quadrats) and $26.0 \pm 4.9 \mathrm{~mm}(\mathrm{n}=150$ individuals) at Croyde, and $6.1 \pm 9.2(\mathrm{n}=23)$ and $28.2 \pm$ $2.7 \mathrm{~mm}(\mathrm{n}=141)$ at Whitsand.

\section{Nucella lapillus predation against Croyde mussels}

The regression slope of $E$ allele frequency as a function of length for the 'rejected' mussels, compared with the control data of 1986-87 (Gardner \& Skibinski 1988) indicated (1) for the Est-D locus, (2) for the Odh locus, and (3) for the dilocus genotype that there was no significant heterogeneity of means about the regres-
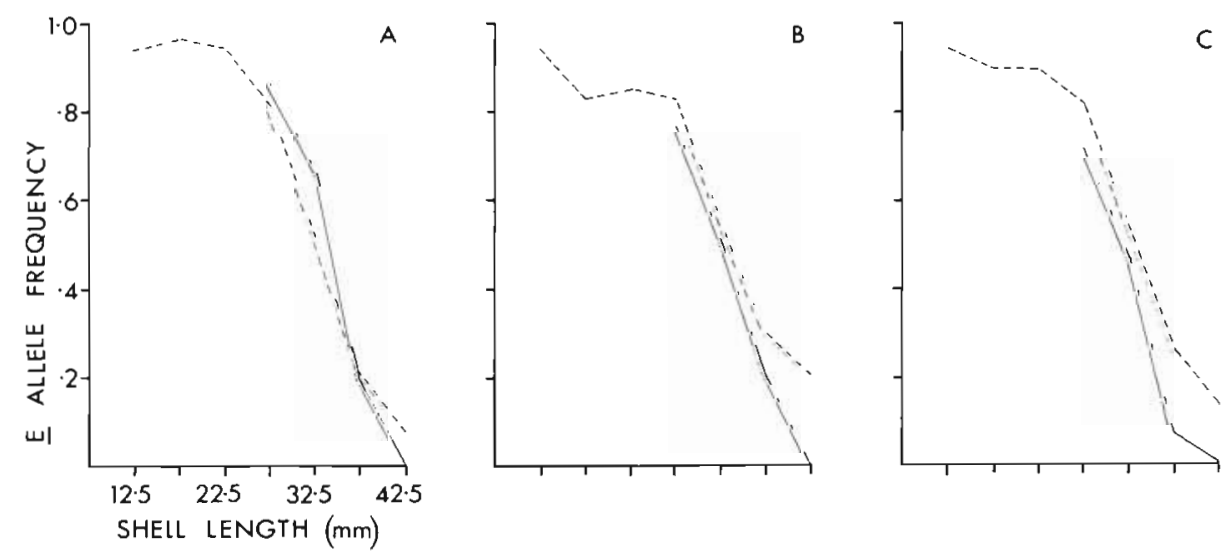

Fig. 1. Mytilus edulis/galloprovincialis. Compound Eallele frequency as a function of length for the 'rejected' category (solid line) of dogwhelk predation against Croyde mussels compared with control data of 1986-87 (broken line) (Gardner \& Skibinski 1988). (A) for the Est-D locus; (B) for the Odh locus; (C) for dilocus genotype 
sion slopes $($ Est-D, $\mathrm{F}=0.501 ;$ Odh, $\mathrm{F}=1.074 ;$ Est $-D+$ Odh, $F=0.694 ; F_{0.05}[1,6]=5.99$ ) (Fig. 1). That mussels 'rejected' by dogwhelks do not differ in length-dependent allele frequencies from a large random sample taken directly from the Croyde population in 1986-87 (Gardner \& Skibinski 1988) indicates that dogwhelks do not prey upon one mussel type in significant preference to another.

\section{Nucella lapillus predation against edulis and galloprovincialis mussels}

A total of 84 mussels were preyed upon by the dogwhelks, of which 79 were edulis and 5 were galloprovincialis. Thus, the dogwhelks expressed a significant preference for edulis over galloprovincialis when the mussels were sampled from allopatric populations $\left(\chi^{2}=32.595, \mathrm{df}=1, \mathrm{p}<0.001\right)$. To see if the dogwhelks would eat galloprovincialis the whelks were not offered a choice in a second experiment but provided with only one galloprovincialis individual. Here the dogwhelks rapidly and successfully fed upon galloprovincialis. Thus, because the dogwhelks will eat galloprovincialis as well as edulis it is clear that when presented with a choice they are actively selecting edulis in preference to galloprovincialis, when the mussels are from allopatric populations.

\section{Morphometric analysis of edulis and galloprovincialis}

Results of the comparison of the morphometric analysis of Bude and Caswell mussels are shown in Table 1. There are no significant differences in mean shell length, mean dry body weight or mean shell weight. However, shell curve is significantly different, with galloprovincialis having a more curved shape than edulis. This is in line with previous descriptions of differences in shell shape between edulis and galloprovincialis (e.g. Seed 1971, Skibinski 1983). The nonsignificant difference in shell length between the samples indicates that any other differences in morphology are not attributable to size differences.

\section{Strength of attachment analysis}

For the sample of 196 mussels, SOA as a function of shell length describes a linear relationship which is highly significant:

$$
\begin{gathered}
\mathrm{SOA}=-5.447+0.226 \text { shell length }(\mathrm{mm}) \\
(\mathrm{R}=0.685, \mathrm{n}=196, \mathrm{p}<0.001) .
\end{gathered}
$$

Regression analysis of SOA as a function of shell length indicates that length and genotype (expressed as dilocus genotype and as $E$ allele number) both explain significant variation in SOA, although site does not (Table 2). Thus for mussels of equal size at the same site, genotype influences strength of attachment. It was not possible to estimate the effect of interactions between length, site and genotype upon SOA because of the low number of individuals of certain genotypes at one or other site. From the combined site SOA data (site does not explain significant variation in SOA) the numbers of individuals and the size range (mm) per genotype were as follows: 93 mussels of 16.6 to $42.5 \mathrm{~mm}$ for the $E / E E / E$ genotype, 18 mussels of 26.1 to $53.5 \mathrm{~mm}$ for the $E / G E / G$ genotype, and 12 mussels of 18.1 to $43.1 \mathrm{~mm}$ for the $G / G G / G$ genotype. Mean values of genotype-dependent $\mathrm{SOA}$ for a $30 \mathrm{~mm}$ mussel (at which length genotype frequencies are approximately equal; Gardner \& Skibinski 1988) predicted from the regression equations are $E / E E / E=1.37 \mathrm{~kg}$, $E / G E / G=1.80 \mathrm{~kg}$ and $G / G G / G=2.20 \mathrm{~kg}$. For the $E$ allele categories these values are $\mathrm{EO}=2.20 \mathrm{~kg}, \mathrm{E} 1=$

Table 1. Mytilus edulis and M. galloprovincialis. Morphometrical comparison of mussels from the Caswell and Bude populations

\begin{tabular}{|c|c|c|c|c|c|c|}
\hline & Population & Mean & SE & $t$ & $p$ & $\mathrm{df}$ \\
\hline $\begin{array}{l}\text { Shell length } \\
(\mathrm{mm})\end{array}$ & $\begin{array}{l}\text { Caswell } \\
\text { Bude }\end{array}$ & $\begin{array}{l}24.790 \\
23.810\end{array}$ & $\begin{array}{l}1.787 \\
1.799\end{array}$ & 0.01 & 0.994 & 58 \\
\hline $\begin{array}{l}\text { Shell curve } \\
(\mathrm{mm})\end{array}$ & $\begin{array}{l}\text { Caswell } \\
\text { Bude }\end{array}$ & $\begin{array}{l}0.084 \\
0.533\end{array}$ & $\begin{array}{l}0.068 \\
0.112\end{array}$ & 3.43 & 0.001 & 58 \\
\hline $\begin{array}{l}\text { Dry body } \\
\text { weight }(g)\end{array}$ & $\begin{array}{l}\text { Caswell } \\
\text { Bude }\end{array}$ & $\begin{array}{l}0.103 \\
0.095\end{array}$ & $\begin{array}{l}0.021 \\
0.019\end{array}$ & 0.28 & 0.777 & 58 \\
\hline $\begin{array}{l}\text { Shell weight } \\
\text { (g) }\end{array}$ & $\begin{array}{l}\text { Caswell } \\
\text { Bude }\end{array}$ & $\begin{array}{l}1.159 \\
1.233\end{array}$ & $\begin{array}{l}0.258 \\
0.249\end{array}$ & 0.21 & 0.838 & 58 \\
\hline
\end{tabular}
respectively 
Table 2. Mytilus edulis/galloprovincialis. Regression analysis of strength of attachment as a function of shell length. Genotype was scored according to dilocus genotype (upper half of table ) and according to $E$ allele number per individual (lower half of table)

\begin{tabular}{|lrrl|}
\hline Source & df & $\begin{array}{c}\text { Sum of } \\
\text { squares }\end{array}$ & Significance \\
\hline Length & 1 & 84.431 & $\mathrm{p}<0.001$ \\
Dilocus genotype & 2 & 6.436 & $\mathrm{p}<0.007$ \\
Site & 1 & 1.548 & $\mathrm{p}>0.120$ \\
Regression & 4 & 122.701 & $\mathrm{p}<0.001$ \\
Residual & 191 & 118.679 & \\
Total & 195 & 241.380 & \\
Length & 1 & 62.158 & $\mathrm{p}<0.001$ \\
Genotype & 4 & 7.650 & $\mathrm{p}<0.02$ \\
(number of E alleles) & & & \\
Site & 1 & 0.262 & $\mathrm{p}>0.50$ \\
Regression & 6 & 123.915 & $\mathrm{p}<0.001$ \\
Residual & 189 & 117.465 & \\
Total & 195 & 241.380 & \\
\hline
\end{tabular}

$2.05 \mathrm{~kg}, \mathrm{E} 2=1.75 \mathrm{~kg}, \mathrm{E} 3=1.71 \mathrm{~kg}$ and $\mathrm{E} 4=1.37 \mathrm{~kg}$. These SOA values thus show a strong negative correlation with increasing $E$ allele number. At any length the SOA of galloprovincialis mussels is greater than that of edulis mussels, and these data correlate with agedependent viability coefficients for the edulis, hybrid and galloprovincialis mussels of Croyde and Whitsand (Gardner \& Skibinski 1991)

\section{DISCUSSION}

The demographic surveys of the Carcinus maenas populations at Croyde and at Whitsand indicate that the green shore crab is unlikely to be a significant mussel predator because it occurs at low frequencies. Furthermore, we have found very little evidence of the characteristic marks left on mussel shells following unsuccessful crab attacks (e.g. Elner 1978, ap Rheinallt $\&$ Hughes 1985). It seems that neither site is particularly suitable for shore crabs, which is in agreement with Hughes \& Drewett (1985) who note that at very exposed locations there are usually very few shore crabs.

The crabs did not express a preference for a particular genotype amongst mussels from Croyde, but the limited range of genotypes offered to the crabs in random tests makes it hard to draw firm conclusions. Whenever possible a morphologically 'edulis' mussel was tested against a morphologically 'galloprovincialis' mussel of equal length, but upon electrophoresis it was determined that in the majority of cases tests had involved 2 edulis-like mussels. This confirms that assessment of mussels from hybrid and allopatric popu- lations based on external morphology is only partially accurate.

Carcinus maenas show no clear preference for a particular mussel type when provided with edulis and galloprovincialis from allopatric populations, and there is no significant difference in the mean sizes of edulis and galloprovincialis mussels eaten. During the tests, on only 5 occasions did a crab attempt to feed upon one mussel but then leave it to feed upon the other ( 3 times from edulis to galloprovincialis, twice from galloprovincialis to edulis). Thus in general the crabs fed upon the first mussel that they came into contact with.

Neither crab sex nor crab size influenced choice of prey. The only significant difference was found to exist between breaking time, $T_{\mathrm{b}}$, for edulis and galloprovincialis, with the former being greater than the latter. The morphometric data for the edulis and galloprovincialis mussels indicate that neither dry body weight nor shell weight differ between these populations, although shell curvature does. The greater edulis $T_{\mathrm{b}}$ probably results because the less ungulate shape of the edulis is harder for the crabs to hold and break than that of the galloprovincialis. However, no obvious differences in crab handling ability of the 2 mussel types were observed. Harger (1972) suggested that the smooth shell of Mytilus edulis from California is harder for crabs to handle, offering less grip than the heavily ridged shell of $M$. californianus. This sort of handling difference is in line with that which might exist between edulis and galloprovincialis.

The Nucella lapillus surveys indicate that dogwhelks are probably the major mussel predator at both Croyde and Whitsand, but this study did not find that dogwhelk predation is largely or totally responsible for the low relative viability coefficient of edulis mussels (Gardner 1989, Gardner \& Skibinski 1991). The E allele frequency as a function of shell length did not differ significantly from data obtained in 1986-87 (Gardner \& Skibinski 1988). Because the size range of mussels (25 to $45 \mathrm{~mm}$ ) used in this study encompasses the length range at which edulis and galloprovincialis occur at equal frequencies it was assumed that the 102 experimental mussels represented a random and similar distribution of edulis-like and galloprovincialis-like genotypes. An extension of this study employing a greater number of mussels might be helpful and provide limited evidence in favour of the above-mentioned hypothesis, especially in light of the results of the dogwhelk predation study for allopatric mussels.

Dogwhelks expressed a significant preference for allopatric edulis over galloprovincialis of an equal size. There was no significant difference in shell weight (thickness) or body weight between edulis and galloprovincialis used in this experiment, so selection of edulis was not made according to differences in ease of 
drilling, or energetic returns of body weight. The basis for this selection is unknown, but might be chemical in nature. However, this does not explain why dogwhelks did not preferentially prey upon edulis-like individuals from amongst mussels of the hybrid Croyde population. A similar situation has been described by Harger (1970) for Mytilus edulis and $M$. californianus from California. Despite the thinner shell and therefore greater ease of accessibility of $M$. edulis to predators, the 2 species of predatory gastropods which prefer $M$. edulis to $M$. californianus did not select mussels on the basis of shell thickness. Neither the way in which the choice is made nor the reason for it are known. Largen (1967) suggested that Nucella lapillus can differentiate large from small mussels so that dogwhelks do not feed upon large mussels as these take too long to drill because of their thicker shells. Largen also suggested that $N$. lapillus probably identifies $M$. edulis from other prey species by chemical stimuli.

At all shell lengths edulis SOA was significantly less than that of galloprovincialis. The genotype-dependent difference in SOA is probably sufficient to account for the positive relationship between alleles at highest frequency in galloprovincialis and shell length which is observed in very many sympatric populations (Skibinski \& Roderick 1991). These data further support suggestions made by Seed (1971), Skibinski (1983) and Gardner \& Skibinski (1988) that a physical selective force acts upon morphological differences between edulis and galloprovincialis.

As mentioned, Harger (1970) demonstrated that the SOA of Mytilus californianus is significantly greater than that of $M$. edulis on the California coast. Mean length and population proportion of $M$. edulis in this region are inversely related to wave exposure. The similarity between this situation and that in SW England is very striking. Whether or not the suggestion that $M$. edulis on the Pacific coast is in fact $M$. galloprovincialis in southern California and $M$. trossulus in regions north of Oregon (McDonald \& Koehn 1988) is correct, it still remains from Harger's (1970) research that species-specific or type-specific differences in SOA exist which are of great significance in explaining the pattern of co-occurrence of these 2 mussel types.

It has been demonstrated for both British (Skibinski et al. 1983) and Irish populations (Gosling \& Wilkins 1981) that galloprovincialis occurs at highest frequency in exposed areas and higher up the shore, whereas edulis occurs at highest frequency in more sheltered areas and lower down the shore. This difference in distribution can, at least in part, be explained by the SOA data. In mixed edulis and galloprovincialis populations, galloprovincialis has an advantage over edulis which is proportional to the degree of exposure. Where wave action is limited in its effect, selection for SOA is also limited such that differential mortality of edulis is small. Where wave action is greatest, at sites such as Croyde and Whitsand, selection for SOA is greatest, and the differential mortality of edulis is high. However, genotype-dependent differences in SOA cannot explain why edulis tends to dominate numerically in sheltered areas, where SOA is not a selective factor. The fact that galloprovincialis does not increase in frequency with increasing shell length in sheltered regions suggests that galloprovincialis recruitment to such areas is limited, or that there is selection against galloprovincialis-like mussels. Many of the sheltered areas of sympatry in which edulis occurs most frequently are estuaries and are therefore subject to salinity fluctuations and lower mean salinities than more coastal waters. A physiological mechanism involving greater galloprovincialis mortality resulting from salinity variation or lower mean salinity can explain the distributional differences of the mussel types between estuarine and coastal waters. Salinity as a genotypedependent cause of mussel mortality has been clearly demonstrated by Koehn et al. (1980) and Hilbish \& Koehn (1985).

The results presented here provide evidence of a mechanism of differential selection. In conjunction with other data (Gardner 1989, Gardner \& Skibinski 1991), which demonstrate that Mytilus galloprovincialis has a significant but small in situ growth advantage over M. edulis (results to the contrary e.g. Skibinski 1983, Skibinski \& Roderick 1989, were based on transplant experiments of smaller sample sizes), we propose that SOA differences, and to a much lesser extent, growth rate differences explain the strong negative correlation between edulis alleles and shell length in hybrid populations from SW England. Whether this is the case for all such hybrid populations can only be determined by further research.

Acknowledgements. The authors thank Mr Eric Roderick for help in the field, and Mrs Donna Gardner for help in the sea water facility. This research was supported in part by a NERC Studentship to J.P.A.G.

\section{LITERATURE CITED}

ap Rheinallt, T (1986). Size selection by the crab Liocarcinus puber feeding on mussels Mytilus edulis and on shore crabs Carcinus maenas; the importance of mechanical factors. Mar Ecol. Prog. Ser 29:45-53

ap Rheinallt, T., Hughes, R. N. (1985). Handling methods used by the velvet swimming crab Liocarcinus puber when feeding on mussels and shore crabs. Mar. Ecol. Prog. Ser 25: $63-70$

Davidson, R. J. (1986). Mussel selection by the paddle crab Ovalipes catharus (White): evidence of flexible foraging behaviour. J. exp. mar Biol. Ecol. 102: 281-299

Dayton, P. K. (1971). Competition, disturbance and commun- 
ity organization: the provision and subsequent utilization of space in a rocky intertidal community. Ecol. Monogr. 41: 351-389

Elner, R. W. (1978). The mechanics of predation by the shore crab, Carcinus maenas (L.) on the edible mussel, Mytilus edulis (L.). Oecologia (Berl.) 36: 333-344

Elner, R. W., Hughes, R. N. (1978). Energy maximization in the diet of the shore crab, Carcinus maenas. J. Anim. Ecol. 47: 103-116

Gardner, J. P. A. (1989). Ecological and population genetics of hybrid mussels from south-west England. Ph.D. thesis, University of Wales

Gardner, J. P. A., Skibinski, D. O. F. (1988). Historical and size-dependent genetic variation in hybrid mussel populations. Heredity 61: 93-105

Gardner, J. P. A., Skibinski, D. O. F. (1991). Growth and mortality differences between the marine mussels Mytilus edulis (L.), Mytilus galloprovincialis (Lmk.) and their hybrids from two sympatric populations in S.W. England. Biol. Bull. mar. biol. Lab., Woods Hole (in press)

Gosling, E. M., Wilkins, N. P. (1981). Ecological genetics of the mussels Mytilus edulis and Mytilus galloprovincialis on Irish coasts. Mar. Ecol. Prog. Ser. 4: 221-227

Harger, J. R. E. (1970). The effect of wave impact on some aspects of the biology of sea mussels. Veliger 12: 401-414

Harger, J. R. E. (1972). Competitive co-existence: maintenance of interacting associations of the sea mussels Mytilus edulis and Mytilus californianus. Veliger 14: $387-410$

Hilbish, T. J., Koehn, R. K. (1985). The physiological basis of natural selection at the Lap locus. Evolution 39: 1302-1317

Hughes, R. N., Drewett, D. (1985). A comparison of the foraging behaviour of dogwhelks, Nucella lapillus (L.), feeding on barnacles or mussels on the shore. J. mollusc. Stud. 51: 73-77

Jubb, C. A., Hughes, R. N., ap Rheinallt, T. (1983). Behavioural mechanisms of size-selection by crabs, Carcinus maenas (L.) feeding on mussels, Mytilus edulis (L.). J. exp. mar. Biol. Ecol. 66: 81-87

Koehn, R. K., Newell, R. I. E., Immerman, F. (1980). Maintenance of an aminopeptidase allele frequency cline by natural selection. Proc. natn. Acad. Sci. USA 77: 5385-5389

Landahl, J. (1988). Sediment-level fluctuation in a mussel bed on a 'protected' sand-gravel beach. Estuar. coast. Shelf Sci. 26: $255-267$

Largen, M. J. (1967). The diet of the dog-whelk, Nucella lapillus. J. Zool. 151: 123-127

McDonald, J. H., Koehn, R. K. (1988). The mussels Mytilus

This article was submitted to the editor galloprovincialis and $M$. trossulus on the Pacific coast of North America. Mar. Biol. 99: 111-118

Sanchez-Salazar, M. E., Griffiths, C. L., Seed, R. (1987). The interactive roles of predation and tidal elevation in structuring populations of the edible cockle, Cerastoderma edule. Estuar. coast. Shelf Sci. 25: 245-260

Seed, R. (1971). A physiological and biochemical approach to the taxonomy of Mytilus edulis L. and Mytilus galloprovincialis Lmk. from south-west England. Cah. Biol. mar. 12: 291-322

Seed, R. (1978). The systematics and evolution of Mytilus galloprovincialis (Lmk). In: Battaglia, B., Beardmore, J. A. (eds.) Marine organisms: genetics, ecology and evolution. Plenum Press, New York, p. 447-468

Seed, R. (1980). Predator-prey relationships between the mud crab Panopeus herbstii, the blue crab Callinectes sapidus, and the Atlantic ribbed mussel Geukensia (Modiolus) demissa. Estuar. coast. Shelf Sci. 11: 445-458

Seed, R. (1982). Predation of the ribbed mussel Geukensia demissa by the blue crab Callinectes sapidus. Neth. J. Sea Res. 16: 163-172

Shanks, A. L., Wright, W. G. (1986). Adding teeth to wave action: the destructive effect of wave-borne rocks on intertidal organisms. Oecologia (Berl.) 69: 420-428

Skibinski, D. O. F. (1983). Natural selection in hybrid mussel populations. In: Oxford, G. S., Rollinson, D. (eds.) Protein polymorphism: adaptive and taxonomic significance. Systematics Association Special Volume No. 24, Academic Press, London and New York, p. 283-298

Skibinski, D. O. F., Beardmore, J. A., Cross, T. F. (1983). Aspects of the population genetics of Mytilus (Mytilidae: Mollusca) in the British Isles. Biol. J. Linn. Soc. 19: 137-183

Skibinski, D. O. F., Roderick, E. E. (1989). Heterozygosity and growth in transplanted mussels. Mar. Biol. 102: 73-84

Skibinski, D. O. F., Roderick, E. E. (1991). Evidence of selective mortality in favour of the Mytilus galloprovincialis Lmk phenotype in British mussel populations. Biol. J. Linn. Soc. (in press)

Sokal, R. R., Rohlf, F. J. (1981). Biometry, 2nd edn. W. H. Freeman and Company, New York

Suckanek, T. H. (1978). The ecology of Mytilus edulis L. in exposed rocky intertidal communities. J. exp. mar. Biol. Ecol. 31: 105-120

Wickens, P. A., Griffiths, C. L. (1985). Predation by Nucella cingulata (Linnaeus, 1771) on mussels, particularly Aulacomya ater (Molina, 1782). Veliger 27: 366-374

Yonge, C. M., Campbell, J. I. (1968). On the heteromyarian condition in the Bivalvia with special reference to Dreissena polymorpha and certain Mytiliacea. Trans. R. Soc. Edinb. 68: 21-43

Manuscript first received: September 18, 1990

Revised version accepted: January 31, 1991 